\title{
The Usefulness of Platelet Distribution Width and Platelet Distribution Width to Lymphocyte Ratio in Predicting Severity and Outcomes in Patients with Snakebite
}

\author{
Ataman Köse, Assoc. Dr., MD ${ }^{1}$; Aydan Akdeniz, Assistant Prof. MD²; Seyran Bozkurt Babus, Assoc. Dr., MD ${ }^{1}$; \\ Mert Göçmen ${ }^{1}$; Gülhan Orekici Temel, Assoc. Dr., $\mathrm{PhD}^{3}$ \\ ${ }^{1}$ Faculty of Medicine, Department of Emergency Medicine, Mersin University, Mersin, Turkey; ${ }^{2}$ Faculty of Medicine, Department of Hematology, \\ Mersin University, Mersin, Turkey; ${ }^{3}$ Faculty of Medicine, Department of Biostatistics and Medical Informatics, Mersin University, Mersin, Turkey
}

\begin{abstract}
Introduction-Tissue damage, inflammatory response, and hematologic abnormalities may occur in snakebite envenomation. This study aimed to evaluate the predictive ability of platelet distribution width (PDW) and platelet distribution width to lymphocyte ratio (PDWLR) in the severity and outcome of envenomation in patients with snakebites in the emergency department (ED).

Methods-All adult patients admitted to the ED after a snakebite were retrospectively evaluated. Patients were classified according to the severity of envenomation. The relationship between the PDW and PDWLR and envenomation severity and patient outcomes was analyzed. Multivariate logistic regression analysis was performed to determine the predictors of severe envenomation. Results were presented as 95\% CIs with odds ratios. Statistical significance was accepted at $P<0.05$.

Results-Envenomation was classified as none/minimal in 42 patients and moderate/severe in 29. PDW and PDWLR were significantly higher in the moderate/severe group $(P=0.016$ and $P<0.001$, respectively). Cut-off values of 16.5 for PDW and 6.15 for PDWLR were related to more severe envenomation (area under the curve $0.67,95 \%$ CI $0.55-0.78$ and area under the curve $0.85,95 \%$ CI: $0.74-0.92$, respectively). Blood product replacement, thrombocytopenia, hematologic abnormality, advanced local findings, compartment syndrome/fasciotomy, antivenom dosing, and moderate/ severe envenomation were associated with PDWLR $>6.15(P<0.05)$. In multivariate analysis, PDWLR (odds ratio 1.19 [95\% CI 1-1.4]; $P=0.04$ ) was an independent predictor of severe envenomation.

Conclusions-Higher PDW and PDWLR were associated with severe envenomation in patients with snakebites in the ED. PDWLR may be used as a predictor of severe envenomation and adverse outcomes.
\end{abstract}

Keywords: envenomation, hematotoxicity effect, platelet indices, emergency medicine

\section{Introduction}

Envenomation from snakebite is a significant health problem worldwide. Approximately 40 to 41 snake species have been reported in Turkey. Of those, 13 to 15 are venomous. Most venomous species are reported to be from the Viperidae family. ${ }^{1-5}$ The venom of such snakes

Corresponding author: Ataman Köse, Faculty of Medicine, Department of Emergency Medicine, Mersin, Mersin University, Turkey; e-mail: ataberk76@yahoo.com.tr.

Submitted for publication April 2020.

Accepted for publication March 2021. usually causes local toxicity and hematotoxicity, whereas neurotoxic effects are relatively rare.

Snakebites may cause regional tissue damage, inflammation through cytokine release, and deterioration in hematologic parameters owing to hematotoxic effects. ${ }^{6}$ Hematologic features may include thrombocytopenia, increased prothrombin time (PT), hypofibrinogenemia, and anemia. ${ }^{7}$ Treatment of venomous snakebites usually aims to correct severe local findings (necrosis, compartment syndrome), hematologic problems, and clotting abnormalities. ${ }^{8}$

Early diagnosis and management are essential in patients with severe envenomation to prevent adverse 
outcomes. In this regard, there is a need for fast and readily accessible aids to guide physicians in such cases. A complete blood count (CBC) is a practical and relatively inexpensive tool to diagnose and monitor systemic envenomation, guide supportive care, and control the antivenom dose. ${ }^{9}$ Platelet count (PLT) is an important parameter in determining the systemic envenomation and severity of snakebites, making PLT and platelet indices of particular value in routine CBC. Recent studies on platelet indices (platelet distribution width [PDW] and mean platelet volume [MPV]) have demonstrated a relationship between platelets and inflammation. ${ }^{10}$ Platelet indices (PDW and MPV) are considered markers of platelet activation, and increased PDW levels have been shown in several conditions. ${ }^{11,12}$ Similar to PLT, platelet indices (MPV, PDW, and the PDW to lymphocyte ratio [PDWLR]) may be indicative for severe envenomation and may therefore be useful for detecting severe envenomation and adverse outcomes. To our knowledge, the significance of these platelet parameters in patients with snakebites has not been reported in the literature.

This study aimed to evaluate the benefit of PDW and PDWLR in predicting the severity of envenomation and clinical outcomes in patients with snakebite in the emergency department (ED).

\section{Methods}

\section{PATIENTS AND SETTING}

This study was approved by the Mersin University faculty of medicine Ethics Committee (01/04/2020; approval no. 2020/249).

All patients aged $\geq 17 \mathrm{y}$ who presented to the ED of Mersin University Hospital with snakebite between January 2011 and November 2019 were evaluated for eligibility in the study. Patients meeting all of the following criteria were included:

1) Patients admitted to the ED with International Classification of Diseases (ICD) codes of T63.0-9, W57, and W59 recorded with the terms "bite, sting, toxic, poisonous" or "envenomation" in the electronic medical record (EMR). Considering the possibility of ICD coding errors, all bites and stings were screened from the ED admission form, and patients with snakebite were included.

2) Patients with a history of exposure to snakebite or patients diagnosed with snakebite who had related local or systemic findings. ${ }^{7}$

3) Patients who had laboratory tests $(\mathrm{CBC}$, biochemistry, and coagulation tests).
Exclusion criteria included (Figure 1) absence of bite marks; lack of an ED patient file, observation form, or clinical information about the clinical course in the EMR; lack of laboratory test results (CBC, biochemistry, and coagulation tests); presence of underlying conditions likely to cause bleeding disorders or affect leukocyte and platelet counts; and erroneous ICD coding of snakebite.

\section{SEVERITY OF ENVENOMATION}

Envenomation was categorized using a 4-grade standard snakebite severity classification system. ${ }^{7}$ The grades were defined as follows: 0: site of the bite alone, without local or systemic sign and symptoms (no envenomation); 1 : minimal tissue swelling and normal laboratory results without systemic symptoms (minimal envenomation); 2 : progressive swelling, mild systemic symptoms with pain, and/or ecchymosis in addition to certain laboratory abnormalities (increased PT and PT-international normalized ratio [INR] and/or thrombocytopenia) (moderate envenomation); and 3: advanced swelling, severe pain, serious systemic symptoms with ecchymosis, necrosis and bullous lesions, coagulopathy, and organ failure (severe envenomation). Envenomations classified as grade 0 or 1 were assigned to the none/minimal group, and those classified as grade 2 or 3 were the moderate/ severe group. The staging from grade 0 to grade 3 depended on the severity of the envenomation and was determined based on the literature in the study planning. A number of the stages were decided by the clinician while caring for the patient in the ED and recorded in the EMR. However, the majority of grading was carried out retrospectively by the researchers. Grading was conducted considering both clinical (local and systemic signs/symptoms) and laboratory values. Cases were separated into 2 groups to aid statistical analysis because of the small sample size. Because the severity of envenomation was not static, to define the cases, laboratory results, clinical findings (local and systemic findings), and treatment/interventions at the time of admission and during follow-up were all evaluated for classification and included in the study. The highest severity score during the patient's treatment was used.

\section{LABORATORY ANALYSIS}

Trends in laboratory values during the follow-up period were recorded. The specific laboratory values were defined before the screening of data. These included white blood cell (WBC) count, neutrophil count, lymphocyte count, hemoglobin, and PLT. Platelet parameters PLT, MPV, PDW, and PDWLR (calculated as PDW divided by the lymphocyte count) were also recorded. Biochemical tests recorded for the study 


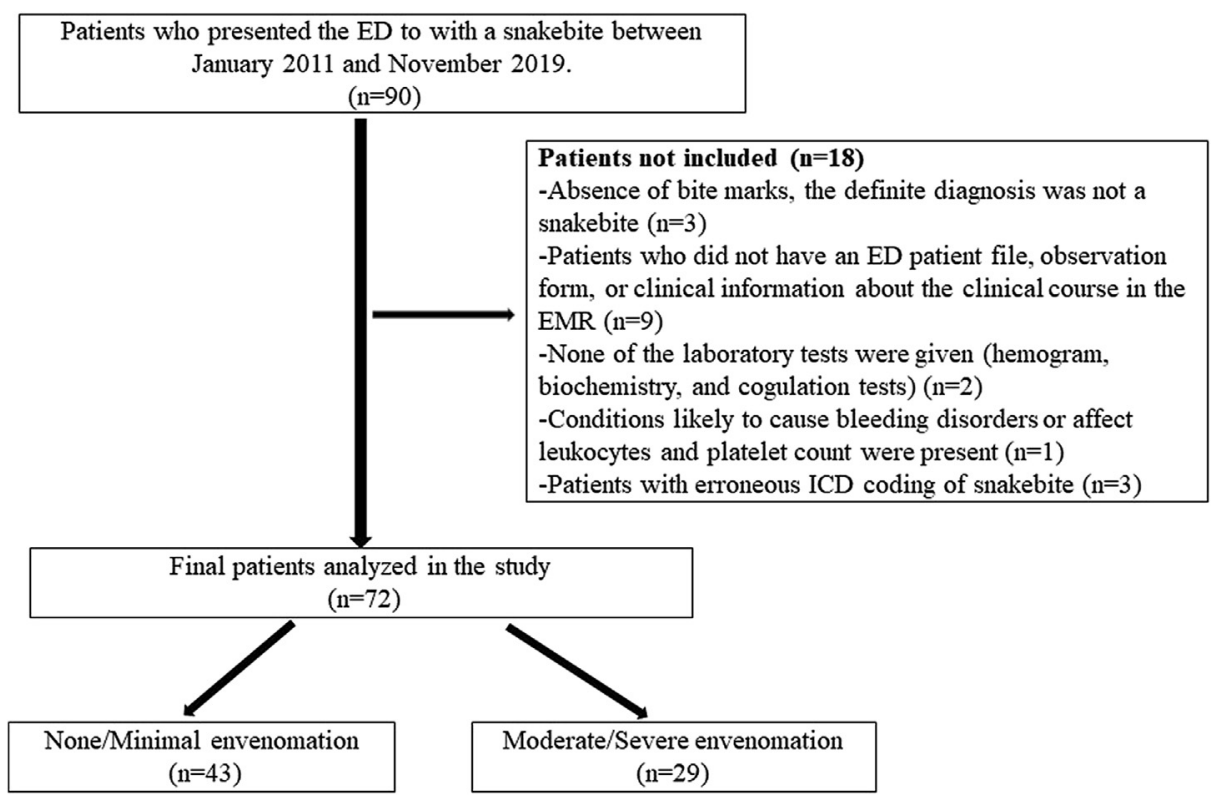

Figure 1. Flow chart of the study population. ED, emergency department; ICD, international classification of diseases; EMR, electronic medical records.

included glucose, sodium, creatinine, C-reactive protein (CRP), and coagulation tests (PT, PTT, PT-INR). Normal reference values for the parameters measured in the study were as follows: leukocyte count $\left(4.5-10.0 \times 103 \cdot \mathrm{L}^{-1}\right)$, platelet count $\left(150-400 \times 103 \cdot \mathrm{L}^{-1}\right)$, MPV $(7.4-10.4 \mathrm{fL})$, PDW (9-17 fL), CRP $\left(0-5 \mathrm{mg} \cdot \mathrm{dL}^{-1}\right)$, and hemoglobin $\left(11.7-16 \mathrm{~g} \cdot \mathrm{dL}^{-1}\right)$. Patients were stratified according to PDWLR cutoff values.

\section{ADVERSE OUTCOMES}

Adverse outcomes were defined as hospitalization, severe local findings, compartment syndrome/amputation, antivenom use, moderate/severe toxicity, the need for any blood product replacement, or any hematologic abnormality.

Hematologic abnormalities were defined as anemia, thrombocytopenia, increased PT, increased PT-INR, and any sign of bleeding. Abnormalities in laboratory values were defined based on the lower or upper limit of reference values. Thrombocytopenia was defined as a platelet count $<150 \times 109 \cdot \mathrm{L}^{-1}$. Severe local findings were defined as progressive swelling and/or necrosis. Blood product replacement was defined as the transfusion of any blood product, mainly fresh frozen plasma. Systemic envenomation was defined as nausea/vomiting, abnormal vital signs, metallic taste in the mouth, weakness, abnormal laboratory test results (anemia, thrombocytopenia, increased PT, increased PT-INR, renal dysfunction), and local or systemic bleeding.

\section{STATISTICS}

The Shapiro-Wilk and Kolmogorov-Smirnov tests were used to assess the normality of distribution. Normally distributed variables were presented as mean \pm SD. Nonnormally distributed variables were expressed as median (25th-75th percentile). Categorical variables were expressed in numbers (percentages). Continuous variables were compared by Student's $t$-test or Mann-Whitney U test as appropriate. A $\chi^{2}$ test was used to evaluate the associations between categorical groups. The area under the curve (AUC) was determined using receiver operating characteristic (ROC) curves to evaluate the predictive ability of PDW/PDWLR in classifying envenomation severity. The ROC curves and AUC values (95\% CIs) were compared. The DeLong method was used to compare the paired AUC. Optimal cut-off values of the variables were estimated using ROC curves and the Youden index. Analysis of one variable at a time was used to describe the strength of the unadjusted association in our data. Significant variables on univariate analysis were analyzed in multiple logistic regression analysis to identify predictors of severe envenomation. Results were presented as a 95\% CIs with odds ratios (ORs). A $P$ value $<0.05$ was considered statistically significant. 
Table 1. Clinical characteristics and laboratory findings of patients with snakebite

\begin{tabular}{|c|c|c|c|c|}
\hline Variables & All $(n=72)$ & $\begin{array}{l}\text { None/Minimal envenomation } \\
(n=43[60 \%])\end{array}$ & $\begin{array}{l}\text { Moderate/Severe } \\
\text { envenomation }(n=29,[40 \%])\end{array}$ & $\mathrm{P}$ value \\
\hline \multicolumn{5}{|l|}{ Clinical characteristics } \\
\hline Age (y) & $45 \pm 14$ & $44 \pm 14$ & $47 \pm 15$ & 0.265 \\
\hline Male sex, n (\%) & $43(60)$ & $29(67)$ & $14(48)$ & 0.104 \\
\hline Comorbidities, n (\%) & $27(38)$ & $14(33)$ & $13(46)$ & 0.239 \\
\hline Diabetes, $\mathrm{n}(\%)$ & $15(21)$ & $7(16)$ & $8(29)$ & 0.215 \\
\hline Cardiovascular disease, n (\%) & $10(14)$ & $8(19)$ & $2(7)$ & 0.158 \\
\hline \multicolumn{5}{|l|}{ Site of the bite, $\mathrm{n}(\%)$} \\
\hline Upper extremity & $46(65)$ & $29(68)$ & $17(62)$ & 0.833 \\
\hline Lower extremity & $23(32)$ & $13(30)$ & $10(36)$ & \\
\hline Trunk and other & $2(3)$ & $1(2)$ & $1(4)$ & \\
\hline $\begin{array}{l}\text { Estimated time to presentation } \\
\text { to } \mathrm{ED}(\mathrm{h})^{a}\end{array}$ & $1.5(1.0-4.5)$ & $1(1.0-2.3)$ & $2.5(1.0-9.0)$ & 0.019 \\
\hline $\begin{array}{l}\text { Systolic blood pressure } \\
\quad(\mathrm{mmHg})\end{array}$ & $128 \pm 19$ & $130 \pm 15$ & $125 \pm 25$ & 0.394 \\
\hline Heart rate (beats $\cdot \min ^{-1}$ ) & $82 \pm 14$ & $78 \pm 11$ & $88 \pm 17$ & 0.015 \\
\hline \multicolumn{5}{|l|}{ Laboratory findings } \\
\hline WBC count $\left(\times 10^{3} \cdot \mathrm{L}^{-1}\right)$ & $10.6 \pm 4.9$ & $8.4 \pm 2.2$ & $13.8 \pm 5.9$ & $<0.001$ \\
\hline Lymphocyte count $\left(\times 10^{3} \cdot \mathrm{L}^{-1}\right)$ & $2.0 \pm 1.1$ & $2.5 \pm 0.1$ & $1.2 \pm 0.8$ & $<0.001$ \\
\hline Hemoglobin $\left(\mathrm{g} \cdot \mathrm{dL}^{-1}\right)$ & $13.6 \pm 1.8$ & $13.6 \pm 1.7$ & $13.5 \pm 2.1$ & 0.866 \\
\hline Platelet count $\left(\times 10^{3} \cdot \mathrm{L}^{-1}\right)$ & $201.8 \pm 83.4$ & $234.4 \pm 58$ & $153.5 \pm 92.3$ & $<0.001$ \\
\hline MPV (fL) & $10.6 \pm 1.1$ & $10.4 \pm 0.9$ & $10.7 \pm 1.4$ & 0.334 \\
\hline PDW (fL) & $13.4 \pm 2.7$ & $12.7 \pm 2.17$ & $14.5 \pm 3.2$ & 0.016 \\
\hline $\operatorname{PDWLR}^{a}$ & $6.4(4.8-12.8)$ & $5.4(3.8-7.4)$ & $12.8(7.2-23.6)$ & $<0.001$ \\
\hline $\mathrm{CRP}^{a}\left(\mathrm{mg} \cdot \mathrm{dL}^{-1}\right)$ & $2(0.8-6.8)$ & $1(0.6-2.8)$ & $5.2(1.6-13.3)$ & $<0.001$ \\
\hline Glucose $\left(\mathrm{mg} \cdot \mathrm{dL}^{-1}\right)$ & $141.5 \pm 57.7$ & $132.4 \pm 60$ & $155.2 \pm 52.3$ & 0.105 \\
\hline Creatinine $\left(\mathrm{mg} \cdot \mathrm{dL}^{-1}\right)$ & $0.7 \pm 0.1$ & $0.7 \pm 0.1$ & $0.7 \pm 0.1$ & 0.053 \\
\hline Sodium $\left(\mathrm{mEq} \cdot \mathrm{L}^{-1}\right)$ & $139.2 \pm 2.8$ & $139.1 \pm 2.7$ & $139.5 \pm 2.9$ & 0.524 \\
\hline PT (s) & $14.1 \pm 2.2$ & $13.5 \pm 1.6$ & $14.9 \pm 2.8$ & 0.021 \\
\hline PT INR & $1.1 \pm 0.2$ & $1.0 \pm 0.1$ & $1.2 \pm 0.2$ & 0.001 \\
\hline PTT (s) & $26.5 \pm 4.3$ & $26.4 \pm 6.1$ & $25.5 \pm 3.9$ & 0.143 \\
\hline \multicolumn{5}{|l|}{ Outcomes } \\
\hline Serious local finding, $\mathrm{n}(\%)$ & $21(29)$ & $0(0)$ & $21(72)$ & $<0.001$ \\
\hline Compartment syndrome, n (\%) & $4(6)$ & $0(0)$ & $4(14)$ & 0.006 \\
\hline Thrombocytopenia, n (\%) & $15(21)$ & $0(0)$ & $15(52)$ & $<0.001$ \\
\hline Hematologic abnormality, n (\%) & $15(21)$ & $0(0)$ & $15(52)$ & $<0.001$ \\
\hline Antivenom dose (vial) ${ }^{a}$ & $1(0-4)$ & $0(0-0)$ & $4(2-4)$ & $<0.001$ \\
\hline Analgesics, n (\%) & $43(60)$ & $15(35)$ & $28(97)$ & $<0.001$ \\
\hline Antibiotics, n (\%) & $34(47)$ & $10(23)$ & $24(83)$ & $<0.001$ \\
\hline Blood replacement, n (\%) & $6(8.3)$ & $0(0)$ & $6(21)$ & 0.001 \\
\hline Hospitalization, n (\%) & $33(46)$ & $7(16)$ & $26(90)$ & $<0.001$ \\
\hline Estimated length of stay (h) ${ }^{a}$ & $55.2 \pm 66.3$ & $15.0 \pm 15.8$ & $114.7 \pm 68.0$ & $<0.001$ \\
\hline
\end{tabular}

CRP, C-reactive protein; ED, emergency medicine; MPV, mean platelet volume; PTT, partial thromboplastin time; PDW, platelet distribution width; PDWLR, platelet distribution width to lymphocyte ratio; PT, prothrombin time.

${ }^{\mathrm{a}}$ Data are expressed as mean \pm SD or numbers (percentage) or median (25th-75th percentile).

\section{Results}

After excluding 18 patients, a total of 72 patients with snakebite were included in the study. Of these, $43 \mathrm{had}$ no/ minimal envenomation and 29 had moderate/severe envenomation. The time from snakebite to $\mathrm{ED}$ was longer $(P=0.019)$ and heart rate was higher $(P=0.015)$ in patients with moderate/severe envenomation. PDW $(P=0.016)$ and PDWLR $(P<0.001)$ were associated with snakebite severity. Analysis of laboratory parameters showed that WBC, CRP, PT, and PT-INR values were significantly higher in the moderate/severe envenomation group $(P<0.05)$. The mean lymphocyte and PLT counts were significantly lower in patients with moderate/severe 


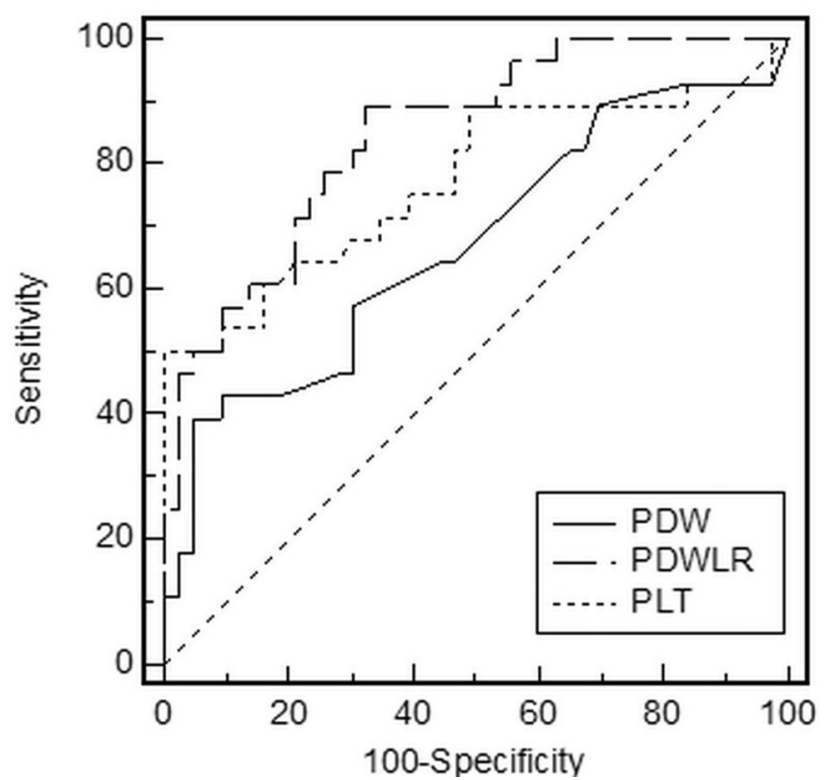

Figure 2. Comparison of ROC curves of PDW, PDWLR, and PLT for the prediction of severe envenomation in patients with snakebite. The dotted line represents the diagonal reference line. ROC, receiver operating characteristic; PDW, platelet distribution width; PDWLR, platelet distribution width to lymphocyte ratio, PLT: platelet.

envenomation $(P<0.001)$. Compartment syndrome $(P=0.006)$, serious local findings, hematologic abnormalities, thrombocytopenia, antivenom dose, analgesic use, antibiotic use, need for blood products, and hospitalization rate and length of stay were higher in patients with moderate/severe envenomation $(P<0.001$; Table 1$)$.

The cutoff values of PDW, PDWLR, and PLT, which predicted moderate/severe envenomation, were obtained from the ROC analysis. In our data, a PDW cutoff of $>16.5$ and a PDWLR cutoff of $>6.15$ were the best fit. The PDWLR cutoff of $>6.15$ had the greatest power to predict more severe envenomation. The AUCs for predicting more severe envenomation using PDW, PDWLR, and PLT counts were 0.67 (95\% CI $0.55-0.78$ ), 0.85 (95\% CI $0.74-0.92)$, and $0.77(95 \% \mathrm{Cl} 0.66-0.86)$, respectively. A comparison of the ROC curves of these parameters revealed that the AUC of PDWLR was more

Table 2. Receiver operating characteristic analysis of variables for the prediction of severe snakebite envenomation

\begin{tabular}{llll}
\hline & $P D W$ & $P D W L R$ & $P L T$ \\
\hline Cut-off & $>16.5$ & $>6.15$ & $\leq 134$ \\
AUC & 0.67 & 0.85 & 0.77 \\
$95 \%$ CI & $0.55-0.78$ & $0.74-0.92$ & $0.66-0.86$ \\
$P$ & 0.012 & $<0.001$ & $<0.001$ \\
\hline
\end{tabular}

AUC, area under the curve; 95\% CI, 95\% confidence intervals; PLT, platelet; PDW, platelet distribution width; PDWLR, Platelet distribution width to lymphocyte ratio. relevant in differentiating minimal and severe envenomation (Figure 2; Table 2).

There was a significant relationship between PDW and PDWLR cutoff values and severity of envenomation $(P<0.001)$. The moderate/severe envenomation rate was $85 \%$ in patients with a PDW of $>16.5$ and $29 \%$ in those with a PDW of $<16.5$. The moderate/severe envenomation rate was $64 \%$ in patients with a PDWLR of $>6.15$, but it was only $9 \%$ in those with a PDWLR of $<6.15$.

Univariate and multivariate logistic regression analysis was performed to examine the relationship between PDW and PDWLR cutoff values and envenomation severity. Initially, only PDW and PDWLR were included in the multivariate logistic regression analysis. In the univariable analysis, PDW $(P=0.002)$ and PDWLR $(P<0.001)$ were associated with severity of envenomation. The rate of severe envenomation in patients with a PDW > 16.5 was 13.26 (95\% CI 2.65-66.31, $P=0.002)$ times higher than in those with a PDW $<16.5$. The rate of severe envenomation in patients with a PDWLR $>6.15$ was 17.26 (95\% CI 4.44-67.04, $P<0.001)$ times higher than in those with a PDWLR $<6.15$. Multivariable analysis revealed that a PDWLR of $>6.15$ was significantly associated with the severity of envenomation (OR 11.28; 95\% CI 2.73-46.51; $P=0.001)$.

Patients with snakebite who had a higher PDWLR value were associated with older age and longer transfer duration $(P<0.05)$. The analysis of laboratory parameters 
Table 3. Relationship between PDWLR cut-off value and clinical parameters

\begin{tabular}{|c|c|c|c|}
\hline Variables & $P D W L R<6.15(n=32)$ & $P D W L R>6.15(n=39)$ & $\mathrm{P}$ value \\
\hline \multicolumn{4}{|l|}{ Clinical characteristics } \\
\hline Age (y) & $41 \pm 13$ & $49 \pm 15$ & 0.037 \\
\hline Male sex, n (\%) & $22(69)$ & $21(54)$ & 0.201 \\
\hline Comorbidities, n (\%) & $10(31)$ & $17(45)$ & 0.248 \\
\hline Diabetes, n $(\%)$ & $5(16)$ & $10(26)$ & 0.278 \\
\hline Cardiovascular disease $\mathrm{n}(\%)$ & $4(12)$ & $6(16)$ & 0.694 \\
\hline \multicolumn{4}{|l|}{ Site of the bite, $\mathrm{n}(\%)$} \\
\hline Upper extremity & $22(69)$ & $23(60)$ & 0.740 \\
\hline Lower extremity & $9(28)$ & $14(37)$ & \\
\hline Trunk and other & $1(3)$ & $1(3)$ & \\
\hline Estimated time to presentation to $\mathrm{ED}(\mathrm{h})^{a}$ & $1(1-2)$ & $2(1-8)$ & 0.009 \\
\hline Systolic blood pressure $(\mathrm{mm} \mathrm{Hg})$ & $131 \pm 14$ & $127 \pm 22$ & 0.359 \\
\hline Heart rate (beats $\cdot \min ^{-1}$ ) & $80 \pm 12$ & $84 \pm 16$ & 0.205 \\
\hline \multicolumn{4}{|l|}{ Laboratory findings } \\
\hline WBC count $\left(\times 10^{3} \cdot \mathrm{L}^{-1}\right)$ & $8.5 \pm 2.1$ & $12.2 \pm 5.9$ & 0.001 \\
\hline Lymphocyte count $\left(\times 10^{3} \cdot \mathrm{L}^{-1}\right)$ & $2.9 \pm 0.8$ & $1.3 \pm 0.8$ & $<0.001$ \\
\hline Hemoglobin $\left(\mathrm{g} \cdot \mathrm{dL}^{-1}\right)$ & $13.6 \pm 1.7$ & $13.6 \pm 1.7$ & 0.992 \\
\hline Platelet count $\left(\times 10^{3} \cdot \mathrm{L}^{-1}\right)$ & $239.1 \pm 66.1$ & $175.7 \pm 82.2$ & 0.001 \\
\hline MPV (fL) & $10.4 \pm 0.8$ & $10.7 \pm 1.4$ & 0.239 \\
\hline $\mathrm{CRP}\left(\mathrm{mg} \cdot \mathrm{dL}^{-1}\right)$ & $1.0(0.6-3.3)$ & $2.2(1.2-8.8)$ & 0.022 \\
\hline Glucose $\left(\mathrm{mg} \cdot \mathrm{dL}^{-1}\right)$ & $128.8 \pm 49.8$ & $152.2 \pm 62.8$ & 0.096 \\
\hline Creatinine $\left(\mathrm{mg} \cdot \mathrm{dL}^{-1}\right)$ & $0.7 \pm 0.1$ & $0.7 \pm 0.2$ & 0.799 \\
\hline Sodium $\left(\mathrm{mEq} \cdot \mathrm{L}^{-1}\right)$ & $139.7 \pm 2.7$ & $138.9 \pm 2.8$ & 0.279 \\
\hline PT (s) & $13.9 \pm 1.6$ & $14.2 \pm 2.5$ & 0.571 \\
\hline PT-INR & $1.0 \pm 0.1$ & $1.1 \pm 0.2$ & $\mathbf{0 . 0 3 0}$ \\
\hline PTT (s) & $27.6 \pm 4$ & $25.7 \pm 4.4$ & 0.066 \\
\hline \multicolumn{4}{|l|}{ Outcomes } \\
\hline Hospitalization, n (\%) & $6(19)$ & $26(67)$ & $<0.001$ \\
\hline Estimated length of stay $(\mathrm{h})^{a}$ & $10.0(6.0-21.5)$ & $48(14-120)$ & $<0.001$ \\
\hline Need for blood replacement, n (\%) & $0(0)$ & $5(13)$ & $\mathbf{0 . 0 1 2}$ \\
\hline Hematologic abnormality, n (\%) & $2(6)$ & $12(31)$ & $\mathbf{0 . 0 1 0}$ \\
\hline Thrombocytopenia, $\mathrm{n}(\%)$ & $2(6)$ & $12(31)$ & 0.010 \\
\hline Compartment syndrome/fasciotomy, n (\%) & $0(0)$ & $4(10)$ & 0.026 \\
\hline Serious local finding, $\mathrm{n}(\%)$ & $3(9)$ & $17(44)$ & 0.001 \\
\hline Antivenom dose (vial) ${ }^{a}$ & $0(0-1)$ & $2(0-4)$ & 0.001 \\
\hline Analgesics, n (\%) & $13(41)$ & $29(74)$ & 0.004 \\
\hline Antibiotics, n (\%) & $10(31)$ & $23(59)$ & $\mathbf{0 . 0 2 0}$ \\
\hline Moderate/Severe envenomation, n (\%) & $3(9)$ & $25(64)$ & $<0.001$ \\
\hline
\end{tabular}

CRP, C-reactive protein; ED, emergency medicine; INR, international normalized ratio; MPV, mean platelet volume; PTT, partial thromboplastin time; PDW, Platelet distribution width; PDWLR, Platelet distribution width to lymphocyte ratio; PT, prothrombin time.

${ }^{\mathrm{a}}$ Data are expressed as mean $\pm \mathrm{SD}$ or numbers (percentage) or median (25th-75th percentiles).

revealed higher CRP levels $(P=0.022)$, WBC count $(P=0.001)$, and PT-INR time $(P=0.03)$ in patients with a PDWLR of $>6.15$. Lower lymphocyte $(P<0.001)$ and PLT $(P=0.001)$ counts were detected in patients with a PDWLR of $>6.15$. Patients with snakebite who had a PDWLR of $>6.15$ were associated with a higher hospitalization rate $(P<0.001)$, a longer length of stay $(P<0.001)$, use of blood product replacement $(P=0.012)$, hematologic abnormalities (thrombocytopenia in particular) $(P=0.010)$, serious local findings $(P=0.001)$, compartment syndrome/fasciotomy $(P=0.026)$, higher antivenom dose $(P=0.001)$, analgesic use $(P=0.004)$, and antibiotic use $(P=0.020)$ (Table 3$)$.

In multiple logistic regression analysis, PDWLR (OR $1.19 ; 95 \%$ CI $1-1.4 ; P=0.04)$ was found to be more significant in evaluating the severity of envenomation in patients with snakebites (Table 4).

No mortality or complications related to antivenom use was recorded. Finger amputation was recorded in 2 patients. 
Table 4. Predictors of severe envenomation in patients with snakebite on multivariate logistic regression analysis

\begin{tabular}{lcc}
\hline Variables & Odds ratio $(95 \%$ CI $)$ & P value \\
\hline Heart rate & $1.04(0.97-1.12)$ & 0.27 \\
PLT & $0.99(0.97-1.03)$ & 0.06 \\
PT & $1.39(0.86-2.23)$ & 0.17 \\
WBC & $1.33(0.95-1.84)$ & 0.09 \\
CRP & $1.11(0.99-1.25)$ & 0.08 \\
PDWLR & $1.19(1-1.40)$ & $\mathbf{0 . 0 4}$ \\
PDW & $1.09(0.73-1.62)$ & 0.66 \\
\hline
\end{tabular}

$\mathrm{CI}$, confidence interval; CRP, C-reactive protein; ED, emergency medicine; MPV, mean platelet volume; PTT, partial thromboplastin time; PDW, platelet distribution width; PDWLR, platelet distribution width to lymphocyte ratio; PT, prothrombin time; PLT, platelet count; WBC, white blood cell.

\section{Discussion}

Snake venom induces enzymatic activities such as metalloproteinase and procoagulant activities (especially in viper and crotalid snakes). These enzymes cause edema, muscle necrosis, hematotoxicity, vascular endothelial lesions, local tissue damage, and inflammatory response. ${ }^{1,8,13-15}$ Additionally, these enzymes may affect the hemostasis cascade, leading to clotting, platelet dysfunction, and thrombocytopenia. ${ }^{14,16}$ In the circulatory system, snake venom not only affects the vascular wall and platelets, but also targets blood cells. White blood cells are highly sensitive and involved in the inflammatory and oxidative response to damage. ${ }^{17}$ Significant rates of leukocytosis, neutrophilia, and lymphopenia have been reported in patients with snake envenomation. ${ }^{3,9,18-20}$ In this study, there was a significant increase in WBC count and a significant decrease in lymphocyte count in the group with moderate/severe envenomation.

Apart from white blood cells and their subgroups, platelets are the dominant cellular elements in the process of thromboinflammation. ${ }^{21}$ Thrombocytopenia is known to be an indicator of the severity of various conditions. At the time of admission, thrombocytopenia directly correlated with the development of systemic bleeding and the severity of snake envenomation. ${ }^{9}$ In critical patients, platelet count and morphology of platelets also change, causing alterations in platelet indices. ${ }^{22,23}$ Increased PDW levels have been observed in several conditions. ${ }^{11,12,24}$ In a retrospective study, low platelet count, high MPV value, and high PDW value were shown to be associated with more severe disease and a higher risk of mortality. ${ }^{25}$ Another study on platelet indices could not find a relationship between MPV, platelet to lymphocyte ratio, and the severity of snakebites. ${ }^{26}$ Another study demonstrated that platelet count and MPV were significantly lower in envenomated blood samples compared to the healthy group. ${ }^{27}$ To the best of our knowledge, there have been no previous studies evaluating PDW and PDWLR in snakebite envenomation.

In this study, PDW and PDWLR were found to be higher in patients with severe envenomation. In particular, PDWLR values $>6.15$ have been associated with adverse outcomes. Although predictability studies based on laboratory value cut-off points were reported previously, different cut-off values were demonstrated. For parameters including CRP, RDW, MPV, and PDW, different cut-off or predictive values have been defined in studies performed on a variety of disorders. Again, although these values were within the normal reference range for MPV, PDW, PLT, CRP, and WBC, many studies have showed that differences in mortality, severity, and adverse outcomes could be seen in various illnesses. ${ }^{22,28-33}$ The cut-off values that were determined in this study were also associated with the severity of envenomation. The sensitivity of PDW was found to be low in ROC analysis; however, PDWLR seems to be more relevant to severity. We also found that PDWLR is superior to PDW in multivariable logistic regression. In addition, we determined that PDWLR is more significant than other routine parameters, such as platelet count, in multivariable logistic regression. Platelet count is a known parameter used in the diagnosis of snakebite severity and patient follow-up in the literature. We suggest that platelet indices such as PDW and PDWLR (especially PDWLR) can be used in addition to clinical and known laboratory parameters (eg, platelet count, fibrinogen, D-Dimer, PT, and PT-INR).

\section{LIMITATIONS}

The primary limitations of this single-center study are the small number of patients and retrospective use of cut-offs that emerged from the data to test the predictive value. This may have reduced the potential statistical power and possibly caused bias. The results of the analysis of these data cannot be generalized to a broader population. A prospective multicenter study involving a large number of patients should be conducted, where cut-off values can be varied. The fact that the species responsible for the snakebite could not be precisely determined confers another limitation. Additionally, other coagulopathic parameters such as D-dimer and fibrinogen levels were not routinely investigated in this population.

\section{Conclusions}

We found a potential relationship between higher PDW and PDWLR values and severe toxicity in patients who presented to the ED with snakebite. We conclude that 
PDW and PDWLR are associated with the severity of envenomation, in addition to the clinical and diagnostic factors previously described in the literature. A PDWLR of $>6.15$ is associated with the need for blood product replacement, hematologic abnormalities, thrombocytopenia, serious local findings, compartment syndrome/ fasciotomy, higher antivenom doses, and longer length of hospital stay. Our data suggest that PDWLR in particular may be used as a predictor of serious envenomation and adverse outcomes. PDWLR is a fast, readily accessible, and inexpensive measure that may be useful to evaluate the severity and guide the management of snakebite. Further studies are needed to evaluate severe envenomation and mortality in a larger patient population and to address the aforementioned limitations.

Author Contributions: Study design (AK, SB); data collection (AK, MG); data analysis (AK, GOT); writing of manuscript (AK, SB, AA); critical revisions (AK, SB, AA). All authors approved the final version of the manuscript.

Financial/Material Support: None.

Disclosures: None.

\section{References}

1. Açikalin A, Gökel Y. Serum IL-6, TNFo levels in snakebite cases occurring in Southern Turkey. Emerg Med J. 2011;28(3):208-11.

2. Sönmez BM, Yılmaz F, Yılmaz MS, Kavalcı C, Gökhan Ş, Akbulut AS, et al. Clinical aspects and emergent management of snakebites presented to emergency department. J Clin Anal Med. 2015;6(5):558-61.

3. Elbey B, Baykal B, Yazgan U, Zengin Y. The prognostic value of the neutrophil/lymphocyte ratio in patients with snakebites for clinical outcomes and complications. Saudi J Biol Sci. 2017;24(2):362-6.

4. Kantarcı E, Kuvandık G, Hamamcı B, Karakuş A. Yılan 1sırması olgularının yönetimi. Journal of Turkish Family Physician. 2018;9(1):25-32.

5. Arikan H, Göçmen B, Kumlutaş Y, Alpagut KN, Ilgaz Ç, Yildız MU. Electrophoretic characterization of the venom samples obtained from various Anatolian snakes (Serpentes: Colubridae, Viperidae, Elapidae). $N$ West $J$ Zool. 2008;4(1):16-28.

6. Teixeira C, Cury Y, Moreira V, Picolob G, Chaves F. Inflammation induced by Bothrops asper venom. Toxicon. 2009;54(7):988-97.

7. Riley BD, Pizon AF, Ruha AM. Snakes and other reptiles. In: Nelson LS, Lewin NA, Howland MA, Hoffman RS, Goldfrank LR, eds. Flomenbaum NE. Goldfrank's Toxicologic Emergencies. 9th ed. New York, NY: McGraw Hill Companies; 2011:1601-9.

8. Agarwal R, Singh AP, Aggarwal AN. Pulmonary oedema complicating snakebite due to Bungarus caeruleus. Singapore Med J. 2007;48(8):e227-30.
9. Santoro ML, Sano-Martins IS, Fan HW, Cardoso JL, Theakston RD, Warrell DA, et al. Haematological evaluation of patients bitten by the jararaca, Bothrops jararaca, in Brazil. Toxicon. 2008;51(8):1440-8.

10. Santimone I, Di Castelnuovo A, De Curtis A, Spinelli M, Cugino D, Gianfagna F, et al. White blood cell count, sex and age are major determinants of heterogeneity of platelet indices in an adult general population: results from the MOLI-SANI project. Haematologica. 2011;96(8):1180-8.

11. Vatankulu MA, Sonmez O, Ertas G, Bacaksiz A, Turfan M, Erdogan E, et al. A new parameter predicting chronic total occlusion of coronary arteries: platelet distribution width. Angiology. 2014;65(1):60-4.

12. Öztürk ZA, Dag MS, Kuyumcu ME, Cam H, Yesil Y, Yilmaz N, et al. Could platelet indices be new biomarkers for inflammatory bowel diseases? Eur Rev Med Pharmacol Sci. 2013;17(3):334-41.

13. Gutierrez JM, Rucavado A. Snake venom metalloproteinases: their role in the pathogenesis of local tissue damage. Biochimie. 2000;82(9-10):841-50.

14. White J. Snake venoms and coagulopathy. Toxicon. 2005;45(8):951-67.

15. Warrell DA. Snake bite. Lancet. 2010;375(9708):77-88.

16. Larréché S, Mion G, Goyffon M. Haemostasis disorders caused by snake venoms. Ann Fr Anesth Reanim. 2008;27(4):302-9.

17. Sharma R, Katkar G, Sundaram M, Paul M, NaveenKumar SK, Swethakumar B, et al. Oxidative stressinduced methemoglobinemia is the silent killer during snakebite: a novel and strategic neutralization by melatonin. J Pineal Res. 2015;59(2):240-54.

18. Moreira V, Dos-Santos MC, Nascimento NG, Borges da Silva H, Fernandes CM, D'Império Lima MR, et al. Local inflammatory events induced by Bothropsatrox snake venom and the release of distinct classes of inflammatory mediators. Toxicon. 2012;60(1):12-20.

19. Zornetta I, Caccin P, Fernandez J, Lomonte B, Gutierrez JM, Montecucco C. Envenomations by Bothrops and Crotalus snakes induce the release of mitochondrial alarmins. PLoS Negl Trop Dis. 2012;6(2):e1526.

20. Cha YS, Lee KH, Lee SJ, Kwon HC, Lee JW, Kim HI, et al. Usefulness of delta neutrophil index for early prediction of overt disseminated intravascular coagulopathy in patients with venomous snakebite. Clin Exp Emerg Med. 2018;5(2):76-83.

21. Teixeira C, Fernandes CM, Leiguez E, ChudzinskiTavassi AM. Inflammation induced by platelet-activating Viperid snake venoms: perspectives on thromboinflammation. Front Immunol. 2019;10:2082.

22. Purbiya P, Golwala ZM, Manchanda A, Sreenivas V, Puliyel JM. Platelet distribution width to platelet count ratio as an index of severity of illness. Indian $J$ Pediatr. 2018;85(1):10-4.

23. Gadó K, Domján G. Thrombocytopenia. Orv Hetil. 2014;155(8):291-303. 
24. Patrick CH, Lazarchick J. The effect of bacteremia on automated platelet measurements in neonates. Am J Clin Pathol. 1990;93(3):391-4.

25. Zhang S, Cui YL, Diao MY, Chen DC, Lin ZF. Use of platelet indices for determining illness severity and predicting prognosis in critically ill patients. Chin Med J (Engl). 2015;128(15):2012-8.

26. Aktar F, Tekin R. Mean platelet volume, neutrophil to lymphocyte ratio, and platelet to lymphocyte ratio in determining the diagnosis or outcome in children with snakebite. Arch Argent Pediatr. 2017;115(6):576-80.

27. Soogarun S, Wiwanitkit V, Suwansaksri J. A trend of platelet indices in patients with green pit viper toxin. Clin Appl Thromb Hemost. 2003;9(4):337-9.

28. Pellicori P, Zhang J, Cuthbert J, Urbinati A, Shah P, Kazmi S, et al. High-sensitivity C-reactive protein in chronic heart failure: patient characteristics, phenotypes, and mode of death. Cardiovasc Res. 2020;116(1):91-100.

29. Park JJ, Choi DJ, Yoon CH, Oh IY, Jeon ES, Kim JJ, et al. Prognostic value of C-reactive protein as an inflammatory and $\mathrm{N}$-terminal probrain natriuretic peptide as a neurohumoral marker in acute heart failure (from the Korean Heart Failure registry). Am J Cardiol. 2014;113(3):511-7.

30. Kurtul A, Acikgoz SK. Usefulness of mean platelet volume-to-lymphocyte ratio for predicting angiographic noreflow and short-term prognosis after primary percutaneous coronary intervention in patients with ST-segment elevation myocardial infarction. Am J Cardiol. 2017;120(4):534-41.

31. Senel T, Ates I, Demir BF, Arikan MF, Karaahmetoglu S, Altiparmak E, et al. The diagnostic and prognostic value of platelet indices in gastrointestinal bleeding. Am J Emerg Med. 2019;37(4):657-63.

32. Lim HH, Jeong IH, An GD, Woo KS, Kim KH, Kim JM, et al. Early prediction of severity in acute ischemic stroke and transient ischemic attack using platelet parameters and neutrophil-to-lymphocyte ratio. $J$ Clin Lab Anal. 2019;33(3), e22714.

33. Tzur I, Barchel D, Izhakian S, Swarka M, Garach-Jehoshua O, Krutkina E, et al. Platelet distribution width: a novel prognostic marker in an internal medicine ward. J Community Hosp Intern Med Perspect. 2019;9(6):464-70. 